\title{
Comparative effects of garlic (Allium sativum) powder and atorvastatin in female reproductive system of hypercholesterolemic rats: $\mathrm{A}$ histological and biochemical evaluation
}

\author{
Sima Jafari ${ }^{\circledR}$, Farah Farokhi $^{1^{*}}$, Abbas Sadeghi ${ }^{\circledR}$ \\ 'Department of Biology, Faculty of Science, Urmia University, Urmia, Iran \\ ${ }^{2}$ Department of Basic Sciences, Faculty of Veterinary Medicine, Shahid Chamran University of Ahvaz, Ahvaz, Iran
}

*Corresponding Author: Farah Farokhi, Department of Biology, Faculty of Science, Urmia University, Urmia, Iran, Tel: +989143460715; Email: f.farokhi@urmia.ac.ir

\begin{abstract}
Background and aims: The abnormal increase in blood cholesterol can cause many problems. Statins have a cholesterol-lowering effect, but they also have adverse effects. Garlic prevents the formation of cholesterol due to its antibiotic properties. This study aimed to investigate the comparative effect of garlic powder and atorvastatin on hypercholesterolemia-induced reproductive failure in female rats.

Methods: In the present experimental study, 48 adult female Wistar rats were divided into eight groups $(\mathrm{n}=6)$, including control, atorvastatin $(10 \mathrm{mg} / \mathrm{kg} / \mathrm{d}$; orally), atorvastatin $(20 \mathrm{mg} / \mathrm{kg} / \mathrm{d}$; orally), garlic powder $(100 \mathrm{mg} / \mathrm{kg} / \mathrm{d}$; orally), hypercholesterolemia $(1.5 \mathrm{mg} / \mathrm{kg} / \mathrm{d}$ of cholesterol; orally), hypercholesterolemia + atorvastatin $(10 \mathrm{mg} / \mathrm{kg} / \mathrm{d})$, hypercholesterolemia + atorvastatin $(20 \mathrm{mg} / \mathrm{kg} / \mathrm{d})$, and hypercholesterolemia + garlic powder. After 30 days, rats were euthanized and blood samples were obtained from their heart for serological assessments. The right ovary was transferred to $10 \%$ formalin for histological analyses, and the left ovary was transferred to a $-80^{\circ} \mathrm{C}$ freezer for evaluation of oxidative stress markers. Data were statistically analyzed by ANOVA and Tukey's test using SPSS version $24.0(P<0.05)$.

Results: The number of healthy primordial, primary, secondary, and antral follicles, catalase activity, total antioxidant capacity (TAOC) as well as estrogen and progesterone levels were lower in hypercholesterolemic rats compared to controls $(P<0.001)$. Additionally, the number of the atretic primary, secondary, and antral follicles and malondialdehyde (MDA) levels were higher in hypercholesterolemic rats $(P<0.001)$. However, garlic powder and atorvastatin 10 improved alterations in the mentioned parameters $(P=0.99)$.

Conclusion: The results showed that hypercholesterolemia could have adverse effects on rat ovaries. However, the garlic powder improves ovarian toxicity in hypercholesterolemia rats better than atorvastatin.

Keywords: Atorvastatin, Garlic, Hypercholesterolemia, Rat, Ovary
\end{abstract}

Received: 9 March 2021, Accepted: 15 May 2021, ePublished: 29 September 2021

\section{Introduction}

Nowadays, many factors are involved in infertility. One of the most important causes of infertility in women is a dysfunction of the reproductive system, which occurs in the form of ovarian or uterine disorders (1). Hypercholesterolemia is a form of hyperlipidemia that is characterized by high cholesterol levels in the blood. The cause of this disease can be environmental (such as morbid obesity and diet) or genetic (2). Evidence suggests that a high level of cholesterol also increases the risk of atherosclerosis, heart attack, transient ischemic attack, stroke, and peripheral vascular disease (3). Previous studies have shown that a high-cholesterol diet, in addition to increasing the number of atretic follicles and decreasing the number of antral follicles, significantly increases luteinizing hormone ( $\mathrm{LH}$ ) and decreases the response of LH to gonadotropin-releasing hormone (4). Studies on the rat models have shown ovarian disorder through an increase in lipid storage. This hypercholesterolemia significantly increases follicular atresia, apoptosis, steroidogenesis, oxidative stress, and caspase- 3 expression $(5,6)$. Many previous studies have shown the association between obesity and ovulation dysfunction (7) and pregnancy disorders (8). It has been hypothesized that obese women show cortisol stability and hypothalamicpituitary-adrenal axis activation (9), which is a strong predictor of ovarian dysfunction and pathogenesis (10). Moreover, a high-fat diet impairs fertility and function of hypothalamic-pituitary-ovarian axis (11).

3-Hydroxy 3-methylglutaryl coenzyme A reductase (HMG-GA) enzyme inhibitors, known as statins, stimulate angiogenesis at low doses by increasing nitric oxide while at high doses, these compounds reduce protein prenylation and inhibit cell growth (12). Atorvastatin is a member of the statin family, which has fewer side effects and is more effective than other statins. Low-dose

(C) 2021 The Author(s); Published by Shahrekord University of Medical Sciences. This is an open-access article distributed under the terms of the Creative Commons Attribution License (http://creativecommons.org/licenses/by/4.0), which permits unrestricted use, distribution, and reproduction in any medium, provided the original work is properly cited. 
atorvastatin has cholesterol-lowering effects as well as beneficial pleiotropic therapeutic effects. Previous studies have shown anti-inflammatory and antioxidant properties of atorvastatin (13). High doses of atorvastatin cause many complications such as reproductive dysfunction, nephrotoxicity, and testicular damage (14).

Garlic, scientifically known as Allium sativum, belongs to the genus Asparagus. The use of this plant is common as a medicinal plant and food flavoring (15). Garlic contains various compounds, including vitamins $\mathrm{A}, \mathrm{C}, \mathrm{B} 1, \mathrm{~B} 2$, and B6, allicin, ajoene, sulfur, and antioxidant compounds. Allicin and ajoene are the most important compounds of this plant. Garlic also has antibiotic properties and prevents the formation of cholesterol. The pharmacological effects of garlic include its antioxidant and protective functions (16). The consumption of garlic extract in patients with high blood cholesterol significantly reduces cholesterol and serum lipids (17).

Therefore, this study aimed to investigate the comparative effect of garlic powder and atorvastatin on hypercholesterolemia-induced reproductive dysfunction in female rats.

\section{Materials and Methods}

Animals and treatment

In the present experimental study, 48 adult female Wistar rats weighing $220 \pm 240 \mathrm{~g}$ were purchased from the Laboratory Animal Breeding Center of Urmia University. They were kept in polycarbonate cages under standard conditions (temperature of $22.00 \pm 2.00^{\circ} \mathrm{C}$; relative humidity of $50.00 \pm 10.00 \%$; light-dark cycles of 12:12 hours) with free access to food and water. Before experimenting, the rats were adapted to laboratory conditions for two weeks. The experimental protocol and procedures were in compliance with international guidelines for care and use of laboratory animals, and they were approved by Urmia University. After two weeks, the rats were divided into eight groups $(n=6)$, including control, atorvastatin $(10 \mathrm{mg} / \mathrm{kg} / \mathrm{d}$; orally), atorvastatin $(20 \mathrm{mg} / \mathrm{kg} / \mathrm{d}$; orally), garlic powder $(100 \mathrm{mg} /$ $\mathrm{kg} / \mathrm{d})$, hypercholesterolemia $(1.5 \mathrm{mg} / \mathrm{kg} / \mathrm{d}$ of cholesterol; orally), hypercholesterolemia + atorvastatin $(10 \mathrm{mg} / \mathrm{kg} / \mathrm{d})$, hypercholesterolemia + atorvastatin $(20 \mathrm{mg} / \mathrm{kg} / \mathrm{d})$, and hypercholesterolemia + garlic powder. Atorvastatin (18) and garlic powder (Goldaru Pharmaceutical Company, Isfahan, Iran) (19) were dissolved in normal saline, and cholesterol was dissolved in sweet almond oil (Nourhan Company, Shiraz, Iran) (20).

\section{Sampling}

After 30 days, the rats were euthanized by intraperitoneal injection of ketamine $\left(75.00 \mathrm{mg} \mathrm{kg}^{-1}\right.$; Alfasan, Woerden, The Netherlands) and xylazine (10.00 mg kg-1; Alfasan, Woerden, The Netherlands). Then, blood samples were taken from the heart for serological assessments. The right ovary was transferred to $10 \%$ formalin for histological analyses, and the left ovary was transferred to a $-80^{\circ} \mathrm{C}$ freezer for evaluation of oxidative stress markers.

\section{Histological analysis}

For histological studies, the ovaries were separated under high magnification using a stereomicroscope (Olympus, Japan). The samples were embedded in paraffin blocks, which were serially cut using a rotary microtome and stained with hematoxylin-eosin (H\&E). For histomorphometric analyses, follicles were classified into primordial and primary $(<70 \mu \mathrm{m})$, early preantral (70-110 $\mu \mathrm{m})$, early antral $(110-200 \mu \mathrm{m})$, and large antral $(>200 \mu \mathrm{m})$. Follicular morphology was examined under a light microscope with $\times 200$ magnification. Follicles with an intact layer of normal granulosa and flattened theca cells, oocytes with normal cytoplasm, and nuclei were considered normal follicles. Follicles were classified as abnormal if dissociation of granulosa cells, early antrum formation, luteinization of granulosa cells, and floatation in the antrum were observed. The follicular count was estimated by counting follicles in all serially prepared slides. Moreover, the atretic primordial and primary, preantral, and antral follicles were counted in serial sections for each sample and compared between groups (21).

\section{Biochemical assay}

To measure lipid peroxidation, the concentration of malondialdehyde (MDA) in ovarian tissue was assessed using the reaction of thiobarbituric acid as previously described (22). Catalase (CAT) activity in homogeneous ovarian tissue was evaluated based on its ability to decompose $\mathrm{H}_{2} \mathrm{O}_{2}$ using Aebi's method (23). The amount of total antioxidant capacity (TAOC) of ovarian tissue was evaluated using the ferric reducing antioxidant power test (24).

To determine estrogen and progesterone levels, the serum concentrations of estrogen and progesterone were assessed by ELISA as described in the instructions provided by the manufacturer (Pars Azmun., Iran).

\section{Statistical analysis}

For statistical analysis, the obtained data were analyzed by one-way ANOVA and Tukey's post-hoc test using SPSS version 24.0. All data were considered statistically significant at $P<0.05$.

\section{Results \\ Histopathological findings}

The mean number of healthy and atretic follicles at different stages is shown in Tables 1 and 2. Histological analysis showed that in the hypercholesterolemic group, the number of healthy primordial, primary, secondary, and antral follicles was significantly lower compared to the control group $(P<0.001)$. The administration of atorvastatin $10 \mathrm{mg} / \mathrm{kg}$ significantly increased the mean number of the healthy primordial, primary, and secondary follicles $(P<0.001, P=0.007, P<0.001$, 
Table 1. The effect of high and low doses of atorvastatin and garlic powder on healthy ovarian follicles in the experimental groups

\begin{tabular}{|c|c|c|c|c|}
\hline Groups & $\begin{array}{c}\text { Number of healthy primordial } \\
\text { follicles }\end{array}$ & $\begin{array}{l}\text { Number of healthy primary } \\
\text { follicles }\end{array}$ & $\begin{array}{l}\text { Number of healthy secondary } \\
\text { follicles }\end{array}$ & $\begin{array}{l}\text { Number of healthy antral } \\
\text { follicles }\end{array}$ \\
\hline Control & $173.20 \pm 6.90^{a}$ & $80.40 \pm 4.50^{a}$ & $54.00 \pm 5.09^{a}$ & $5.40 \pm 0.899^{a}$ \\
\hline Atro10 & $151.20 \pm 7.32^{b}$ & $78.20 \pm 4.43^{\mathrm{a}}$ & $37.80 \pm 2.28^{b}$ & $4.20 \pm 0.83 \mathrm{ab}$ \\
\hline Atro20 & $138.20 \pm 5.93^{b}$ & $67.00 \pm 4.84^{b}$ & $36.80 \pm 1.64^{b}$ & $3.80 \pm 0.44 a b$ \\
\hline Garlic & $173.80 \pm 8.16^{a}$ & $78.60 \pm 4.61^{a}$ & $51.40 \pm 5.31^{a}$ & $5.20 \pm 0.83^{\mathrm{a}}$ \\
\hline Hyper & $77.20 \pm 7.25^{c}$ & $36.20 \pm 2.58^{c}$ & $20.40 \pm 1.14^{c}$ & $2.20 \pm 0.83^{c}$ \\
\hline Hyper + Atro10 & $117.20 \pm 10.49^{d}$ & $47.00 \pm 4.84^{d}$ & $36.00 \pm 2.12^{b}$ & $3.20 \pm 1.09$ bc \\
\hline Hyper + Atro20 & $109.40 \pm 11.14^{d}$ & $43.40 \pm 2.50 \mathrm{dc}$ & $30.00 \pm 2.34^{d}$ & $3.00 \pm 0.70 \mathrm{bc}$ \\
\hline Hyper + Garlic & $166.60 \pm 9.93^{a}$ & $74.60 \pm 4.92^{\mathrm{a}}$ & $48.20 \pm 4.60^{a}$ & $4.80 \pm 0.83^{a}$ \\
\hline
\end{tabular}

a,b,c,d Different letters indicate a significant difference between groups in each column $(P<0.05)$.

Table 2. The effect of hypercholesterolemia (Hyper), high and low doses of atorvastatin and garlic powder on the number of corpus luteum and atretic ovarian follicles in the experimental groups

\begin{tabular}{lccc}
\hline Groups & $\begin{array}{c}\text { Number of atretic primary } \\
\text { follicles }\end{array}$ & $\begin{array}{c}\text { Number of atretic secondary } \\
\text { follicles }\end{array}$ & $\begin{array}{c}\text { Number of atretic antral } \\
\text { follicles }\end{array}$ \\
\hline Control & $8.20 \pm 1.64^{\mathrm{a}}$ & $6.40 \pm 0.89^{\mathrm{a}}$ & $4.80 \pm 0.83^{\mathrm{a}}$ \\
Atro10 & $13.20 \pm 0.83^{\mathrm{b}}$ & $9.00 \pm 1.22^{\mathrm{b}}$ & $5.20 \pm 0.83^{\mathrm{a}}$ \\
Atro20 & $14.60 \pm 1.14^{\mathrm{b}}$ & $9.80 \pm 0.83^{\mathrm{b}}$ & $6.40 \pm 1.14^{\mathrm{ab}}$ \\
Garlic & $8.80 \pm 1.64^{\mathrm{a}}$ & $5.40 \pm 0.89^{\mathrm{a}}$ & $5.40 \pm 1.14^{\mathrm{a}}$ \\
Hyper & $29.60 \pm 2.07^{\mathrm{c}}$ & $18.40 \pm 2.30^{\mathrm{c}}$ & $14.40 \pm 1.14^{\mathrm{c}}$ \\
Hyper + Atro10 & $22.20 \pm 1.30^{\mathrm{d}}$ & $9.60 \pm 1.51^{\mathrm{b}}$ & $8.00 \pm 1.22^{\mathrm{bd}}$ \\
Hyper + Atro20 & $26.80 \pm 1.78^{\mathrm{c}}$ & $12.20 \pm 0.83^{\mathrm{d}}$ & $23.40 \pm 1.51^{\mathrm{a}}$ \\
Hyper + Garlic & $12.80 \pm 2.58^{\mathrm{b}}$ & $6.60 \pm 1.14^{\mathrm{a}}$ & $9.40 \pm 1.14^{\mathrm{d}}$
\end{tabular}

$\overline{a, b, c, d}$ Different letters indicate a significant difference between groups in each column $(P<0.05)$.

respectively), but the number of antral follicles was not significantly different from the hypercholesterolemic group $(P=0.556)$. Administration of atorvastatin 20 $\mathrm{mg} / \mathrm{kg}$ significantly increased the mean number of healthy primordial and secondary follicles $(P<0.001$, $P=0.002$, respectively), however, the number of primary and antral follicles was not significantly different from the hypercholesterolemic group $(P=0.169, P=0.788$, respectively). Garlic powder could improve the mean number of healthy follicles in hypercholesterolemic rats better than atorvastatin. Thus, in the group receiving garlic powder with hypercholesterolemia, the mean number of healthy primordial, primary, secondary and antral follicles was not significantly different from the control group $(P=0.921, P=0.407, P=0.170, P=0.942$, respectively; Table 1, Figures 1 and 2 ).

The mean number of primary, secondary, and antral atretic follicles in hypercholesterolemic rats showed a significant increase compared to the control group $(P<0.001)$. Low-dose administration of atorvastatin showed a significant reduction in the mean number of primary, secondary, and antral atretic follicles compared to the hypercholesterolemic group $(P<0.001)$. However, high dose atorvastatin could not cause a significant difference in the mean number of primary atretic follicles compared to the hypercholesterolemic rats $(P=0.195)$. The administration of garlic powder to hypercholesterolemic rats showed a reduction in the mean number of primary, secondary, and antral atretic follicles compared to the hypercholesterolemic group ( $P<0.001, P<0.001, P=0.001$, respectively), so that the mean number of secondary and antral atretic follicles of hypercholesterolemic rats receiving garlic powder was not significantly different from the control rats $(P=0.99, P=$ 0.307 , respectively; Table 2, Figures 1 and 2)

The mean number of corpus luteum in hypercholesterolemic rats showed a significant decrease compared to control groups $(P<0.001)$. In the hypercholesterolemic group receiving low-dose atorvastatin, the mean number of corpus luteum was not significantly different from the control group $(P=0.275)$. The administration of a high dose of atorvastatin to hypercholesterolemic rats showed an increase in the mean number of corpus luteum compared to hypercholesterolemia group $(P=0.001)$. The administration of garlic powder could improve the mean number of corpus luteum in hypercholesterolemic rats, indicating no significant difference from the control rats $(P=0.131$; Table 2, Figures 1 and 2).

\section{Biochemical study of ovarian tissues}

The estrogen level was significantly lower in hypercholesterolemic rats compared to the control group $(P<0.001)$, while this value in the hypercholesterolemic + garlic powder group was nearly restored to the control group levels $(P=0.99)$. However, the administration 

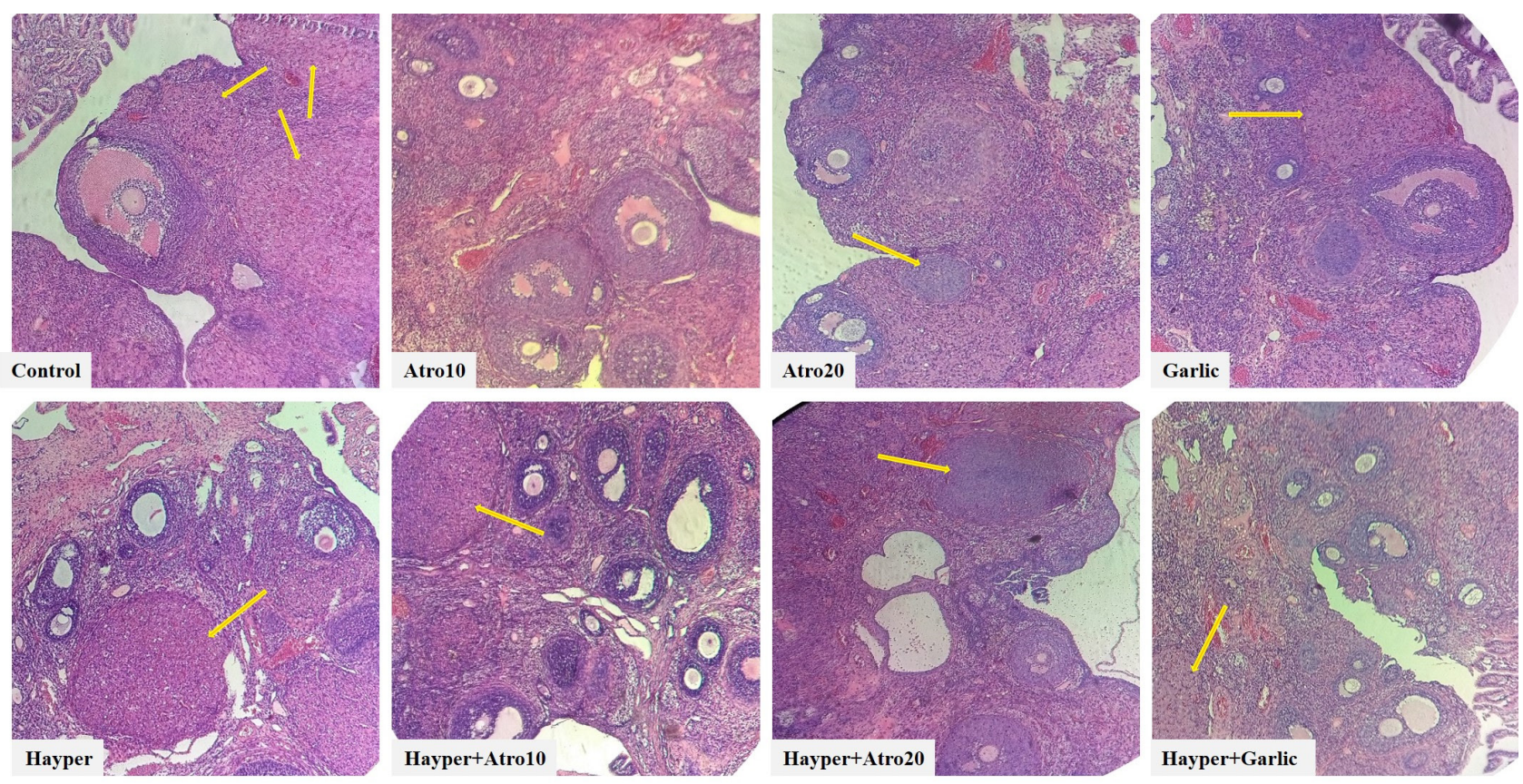

Figure 1. Cross-section of the ovary in different experimental groups with hematoxylin and eosin staining ( $\times 100$ magnification). Arrow indicates the corpus luteum.
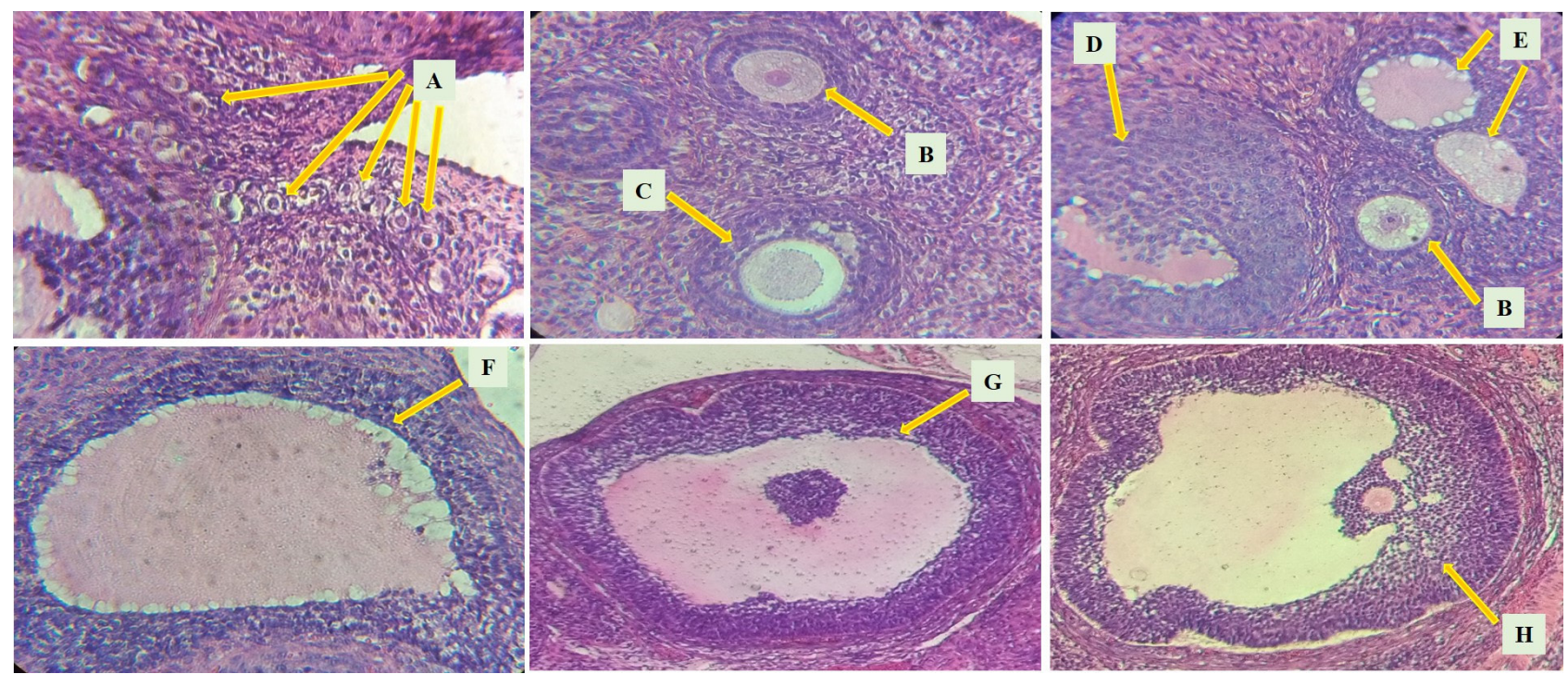

Figure 2. Cross-section of the ovary in different experimental groups (H\&E staining, $\times 400$ magnifications). A: Healthy Primordial Follicle, B: Healthy Primary Follicle, C: Healthy Secondary Follicle, D: Atretic Preantral Follicle, E: Secondary Atretic Follicle, F: Cystic Ovarian Follicle, G: Atretic Antral Follicle, H: Healthy Antral Follicle

of the low $(P=0.111)$ and high $(P=0.99)$ doses of atorvastatin to hypercholesterolemic rats did not show an increase in serum estrogen levels compared to the hypercholesterolemic group, indicating no significant difference (Figure 3).

The progesterone level was significantly lower in hypercholesterolemic rats compared to the controls $(P<0.001)$. However, the progesterone level in hypercholesterolemic rats receiving high and low doses of atorvastatin groups showed a significant increase compared to the hypercholesterolemic rats $(P<0.001)$. The level of this hormone in the hypercholesterolemic + garlic powder group was not significantly different from the control group $(P=0.662$; Figure 3$)$.

The MDA concentration was significantly lower in hypercholesterolemic rats compared to controls $(P<0.001)$, while there was no significant difference in hypercholesterolemic rats receiving low $(P=0.973)$ and high $(P=0.857)$ doses of atorvastatin and garlic powder $(P=0.99)$ compared to the control group (Figure $4 \mathrm{~A})$.

CAT activity showed a significant decrease in the hypercholesterolemic group compared to the control rats $(P<0.001)$. While in the hypercholesterolemic rats receiving low $(P=0.074)$ and high $(P=0.061)$ doses of atorvastatin and garlic powder $(P=0.008)$, the activity of this enzyme had a significant increase compared to the 


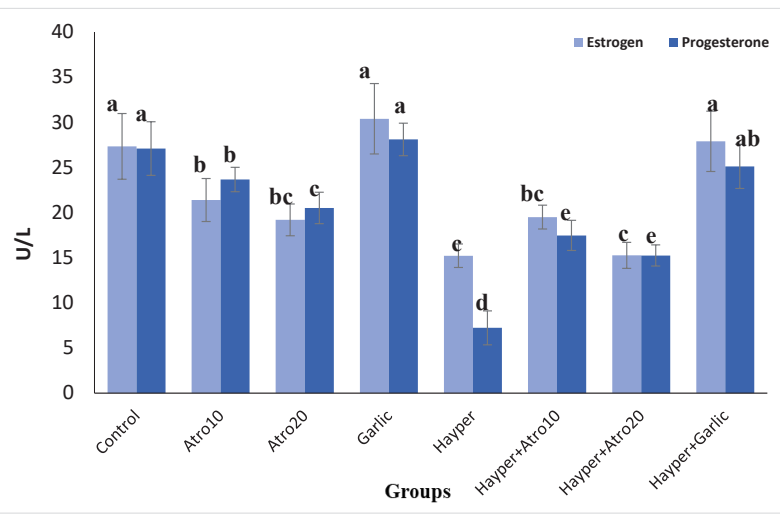

Figure 3. Comparative Effects of garlic powder and atorvastatin on estrogen and progesterone levels of hypercholesterolemia rats. All data are presented as mean \pm SD. a, b, c, d, and e represent significant differences $(P<0.05)$ between groups.

hypercholesterolemic rats (Figure 4B).

TAOC in hypercholesterolemic rats showed a significant decrease compared to controls $(P<0.001)$. However, the administration of garlic powder to hypercholesterolemic rats showed an increase in the TAOC, so that it did not show a significant difference from the control rats $(P=0.976)$. In the hypercholesterolemia groups receiving low $(P=0.002)$ and high $(P=0.018)$ doses of atorvastatin, the TAOC was significantly higher compared to the hypercholesterolemia group, however, it was significantly lower compared to the control rats $(P=0.001$; Figure $4 C)$.

\section{Discussion}

Genetic and environmental factors play important roles in obesity; a high-fat diet is the most important environmental factor that causes this disease. Studies have shown that hypercholesterolemia is associated with metabolic disorders, especially obesity and insulin resistance, infertility, menstrual irregularities, and anovulation (25). Increased body fat is associated with leptin hormone level and weight gain occurs due to changes in this hormone levels (26). Leptin hormone is made in fat cells and binds to leptin receptors, which are encoded by the LEPR gene. This hormone acts as a sensor of fat mass, and its concentration in the bloodstream is associated with the storage of body fat (27). It seems that in hypercholesterolemic rats, a disorder in the secretion of this hormone causes metabolic disorders and obesity due to an increase in cholesterol levels in the body. Cholesterol accumulation affects the fluidity and stability of cell membranes and causes cell damage (28). Moreover, the accumulation of fatty acids, including pristanic acid, causes Zellweger syndrome in the brain; and a cholesterol-rich diet can cause changes in pituitary gland function (29). Changes in pituitary gland function lead to disorder in the LH and FSH secretion, which causes large alterations in the menstrual cycle and reduces the number of healthy follicles (30).

In this study, the number of atretic follicles in the hypercholesterolemic group was significantly higher compared to the control and other groups. However, the administration of garlic powder and atorvastatin 10 significantly reduced the number of atretic follicles. Evidence suggests that apoptosis in granulosa cells is the principal mechanism of ovarian follicle atresia (31). Significant reduction in the percentage of atretic follicles in this study indicates the beneficial properties of these compounds in inhibiting the apoptosis process and reducing follicular atresia. Previous studies have shown that some factors, such as obesity, especially abdominal obesity, can cause oxidative stress (32). A high-fat diet leads to severe oxidative stress in cells by increasing reactive oxygen species (ROS) production. Additionally, a high concentration of androgens in follicular fluid is associated with highLHlevels, which maycausefollicular degeneration
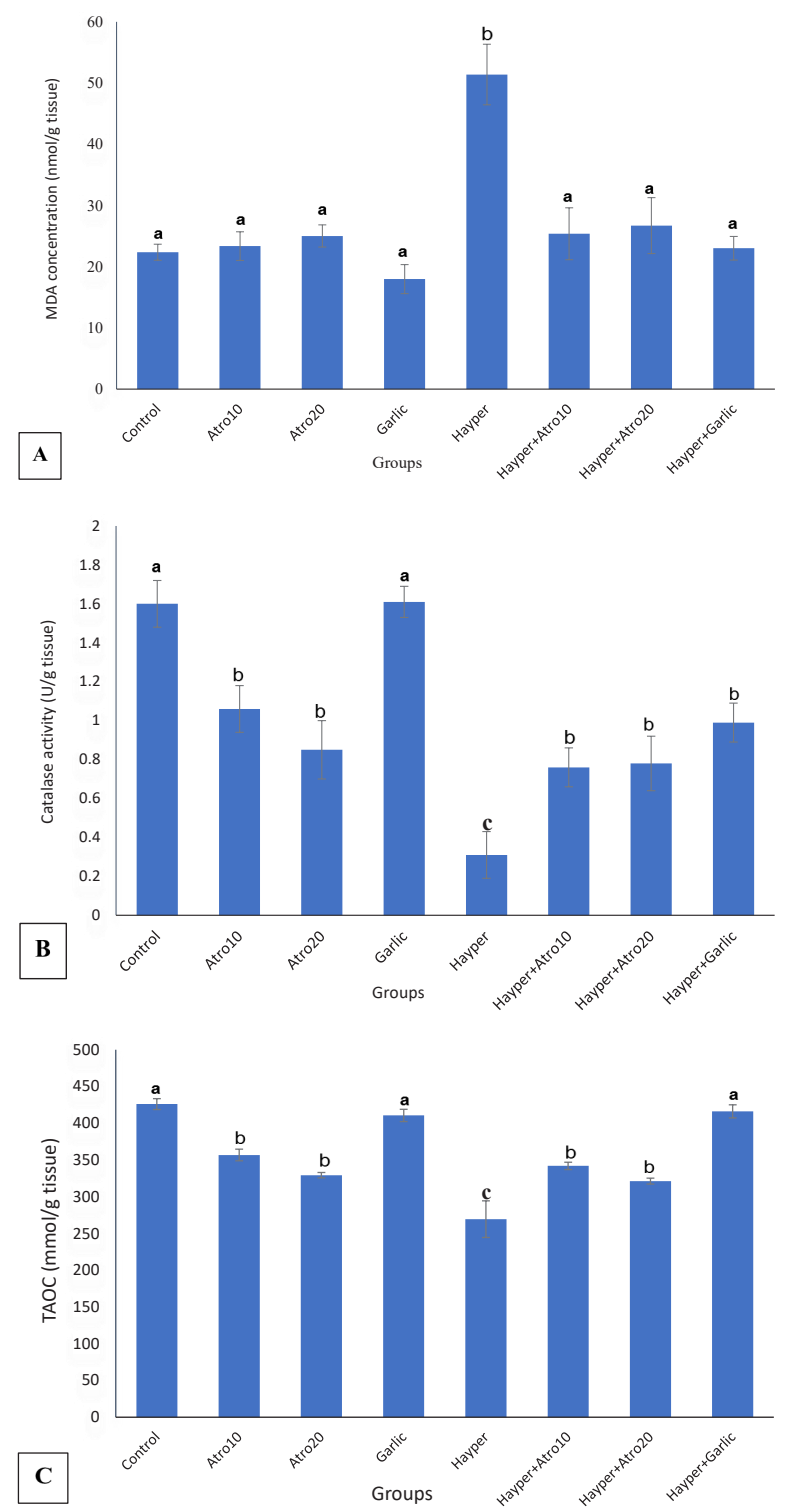

Figure 4. Effects of garlic powder and atorvastatin on MDA Concentration (A), Catalase Activity (B), and TAOC (C) in the Ovaries of Hypercholesterolemic Rats. a,b, and c represent significant differences $(P<0.05)$ between groups. Results are presented as means \pm standard deviation. MDA: Malondialdehyde; TAOC: Total antioxidant capacity. 
and inhibit follicle development (33). Ovarian cysts can cause ROS production, high levels of oxidative stress such as MDA, and decreased total serum antioxidant capacity in patients with polycystic ovary syndrome (34). The level of oxidative stress is measured by various indicators, such as MDA level, catalase activity, and TAOC. In the present study, the MDA concentration significantly increased due to hypercholesterolemia. In addition, the catalase enzyme activity and TAOC significantly reduced due to hypercholesterolemia. This action indicates oxidative stress due to hypercholesterolemia, which may be due to an increase in the number of cystic follicles or atretic follicles due to hypercholesterolemia. The inhibitory effect of cholesterol accumulation in the pituitary gland causes unbalanced changes in $\mathrm{LH}$ secretion. A change in the amount of LH hormone leads to anovulation and consequently a decrease in corpus luteum. The increase in atretic follicles and decrease in healthy follicles decrease the number of follicles that have completed ovulation and cause a reduction in the number of corpus luteum (35).

Garlic has anti-diabetic properties that cause a change in the activity of the glutathione reductase enzyme and significantly reduces the activity of CAT and superoxide dismutase (36). Antioxidant and anti-inflammatory effects of atorvastatin have been demonstrated. Most researchers attribute these effects to the inhibition of the production of malonic acid, which is involved in the synthesis of isoprenoids. Malonic acid is a product of the HMG-COA reductase enzyme and the source of isoprenoids that play an important role in intracellular functions such as apoptosis, inflammation, coagulation, migration, and adhesion of leukocytes. Accordingly, the inhibition of isoprenoid synthesis by statins can be useful as a protective mechanism in cellular damage (37). Previous studies have shown that subcutaneous administration of atorvastatin prevents the production of anion superoxide by reducing NADPH oxidase activity (38). Therefore, the reduction in the number of atretic follicles due to the administration of garlic powder and atorvastatin can be due to the reduction of inflammatory factors, reduction of oxidative stress, and loss of ROS due to the antioxidant properties of garlic (39) and atorvastatin (40).

\section{Conclusion}

According to the results of this study, it can be concluded that hypercholesterolemia causes changes in ovarian tissue, hormone balance, and oxidative stress, and the administration of garlic powder can have positive effects on the above-mentioned parameters. Further, the effects of atorvastatin are dose-dependent because atorvastatin $10 \mathrm{mg} / \mathrm{kg}$ improved hypercholesterolemia better than atorvastatin $20 \mathrm{mg} / \mathrm{kg}$. Therefore, due to the adverse effects of atorvastatin on other organs, it is possible to use garlic powder to treat hypercholesterolemia instead of atorvastatin.
Conflict of Interests

The authors declare no conflict of interest.

\section{Ethical Approval}

All experiments were carried out according to Ethical Guidelines for the Care and Use of Laboratory Animals. This study was approved by the Ethics Committee of Urmia University (No: IRUU-AEC-23/AD/3, 2021/4/7).

Authors' Contributions

FF conceived and designed the experiment and was responsible for overall supervision. SJ performed laboratory tests and data collection. AS contributed to all experimental works and analysis of data. All authors read and approved the final manuscript.

\section{Acknowledgements}

This article was derived from a master's thesis in Histology and Embryology at Urmia University, Urmia, Iran (Thesis Number: 2A-406, 2017-2018). The authors appreciate Department of Biology, Faculty of Science, and Urmia University Research Council for supporting this research.

\section{References}

1. Vander Borght M, Wyns C. Fertility and infertility: definition and epidemiology. Clin Biochem. 2018;62:2-10. doi: 10.1016/j.clinbiochem.2018.03.012.

2. Mărginean $\mathrm{CO}$, Mărginean $\mathrm{C}$, Meliț LE. New insights regarding genetic aspects of childhood obesity: a minireview. Front Pediatr. 2018;6:271. doi: 10.3389/fped.2018.00271.

3. Iyen B, Qureshi N, Kai J, Akyea RK, Leonardi-Bee J, Roderick P, et al. Risk of cardiovascular disease outcomes in primary care subjects with familial hypercholesterolaemia: a cohort study. Atherosclerosis. 2019;287:8-15. doi: 10.1016/j. atherosclerosis.2019.05.017.

4. El-Sayyad HIH, El-Shershaby EMF, El-Mansi AA, El-Ashry NE. Anti-hypercholesterolemic impacts of barley and date palm fruits on the ovary of Wistar albino rats and their offspring. Reprod Biol. 2018;18(3):236-51. doi: 10.1016/j. repbio.2018.07.003.

5. Lin YJ, Tsai CC, Huang LT, Sheen JM, Tiao MM, Yu HR, et al. Detrimental effect of maternal and post-weaning high-fat diet on the reproductive function in the adult female offspring rat: roles of insulin-like growth factor 2 and the ovarian circadian clock. J Assist Reprod Genet. 2017;34(6):817-26. doi: 10.1007/s10815-017-0915-5.

6. Kannan S, Srinivasan D, Raghupathy PB, Bhaskaran RS. Association between duration of obesity and severity of ovarian dysfunction in rat-cafeteria diet approach. J Nutr Biochem. 2019;71:132-43. doi: 10.1016/j. jnutbio.2019.05.012.

7. Goldsammler M, Merhi Z, Buyuk E. Role of hormonal and inflammatory alterations in obesity-related reproductive dysfunction at the level of the hypothalamic-pituitaryovarian axis. Reprod Biol Endocrinol. 2018;16(1):45. doi: 10.1186/s12958-018-0366-6.

8. Stubert J, Reister F, Hartmann S, Janni W. The risks associated with obesity in pregnancy. Dtsch Arztebl Int. 2018;115(16):276-83. doi: 10.3238/arztebl.2018.0276.

9. Al-Safi ZA, Polotsky A, Chosich J, Roth L, Allshouse AA, Bradford AP, et al. Evidence for disruption of normal circadian cortisol rhythm in women with obesity. Gynecol Endocrinol. 2018;34(4):336-40. doi: 
10.1080/09513590.2017.1393511.

10. Baskind NE, Balen AH. Hypothalamic-pituitary, ovarian and adrenal contributions to polycystic ovary syndrome. Best Pract Res Clin Obstet Gynaecol. 2016;37:80-97. doi: 10.1016/j.bpobgyn.2016.03.005.

11. Hohos NM, Skaznik-Wikiel ME. High-fat diet and female fertility. Endocrinology. 2017;158(8):2407-19. doi: 10.1210/ en.2017-00371.

12. Mo H, Jeter R, Bachmann A, Yount ST, Shen CL, Yeganehjoo $\mathrm{H}$. The potential of isoprenoids in adjuvant cancer therapy to reduce adverse effects of statins. Front Pharmacol. 2018;9:1515. doi: 10.3389/fphar.2018.01515.

13. Crevar-Sakac M, Vujić Z, Kotur-Stevuljević J, Ivanisević J, Jelić-Ivanović Z, Milenković $M$, et al. Effects of atorvastatin and artichoke leaf tincture on oxidative stress in hypercholesterolemic rats. Vojnosanit Pregl. 2016;73(2):178-87. doi: 10.2298/vsp140917148c.

14. Hamzeh M, Hosseinimehr SJ, Mohammadi HR, Yaghubi Beklar S, Dashti A, Talebpour Amiri F. Atorvastatin attenuates the ovarian damage induced by cyclophosphamide in rat: an experimental study. Int J Reprod Biomed. 2018;16(5):323-34.

15. El-Saber Batiha G, Magdy Beshbishy A, Wasef LG, Elewa YHA, Al-Sagan AA, Abd El-Hack ME, et al. Chemical constituents and pharmacological activities of garlic (Allium sativum L.): a review. Nutrients. 2020;12(3):872. doi: 10.3390/nu12030872.

16. Musavi H, Tabnak M, Alaei Sheini F, Hasanzadeh Bezvan $\mathrm{M}$, Amidi F, Abbasi M. Effect of garlic (Allium sativum) on male fertility: a systematic review. J HerbMed Pharmacol. 2018;7(4):306-12. doi: 10.15171/jhp.2018.46.

17. Sun YE, Wang W, Qin J. Anti-hyperlipidemia of garlic by reducing the level of total cholesterol and low-density lipoprotein: a meta-analysis. Medicine (Baltimore). 2018;97(18):e0255. doi: 10.1097/md.0000000000010255.

18. Stumpf C, Petzi S, Seybold K, Wasmeier G, Arnold M, Raaz D, et al. Atorvastatin enhances interleukin-10 levels and improves cardiac function in rats after acute myocardial infarction. Clin Sci (Lond). 2009;116(1):45-52. doi: $10.1042 / \mathrm{cs} 20080042$.

19. Khalaf G. A histological study on the possible protective role of garlic in diabetes-induced structural changes in the renal cortex of adult male albino rats. Egypt J Histol. 2012;35(4):812-21. doi: 10.1097/01. ehx.0000419784.46088.83.

20. El-Beshbishy HA, Singab AN, Sinkkonen J, Pihlaja K. Hypolipidemic and antioxidant effects of Morus alba L. (Egyptian mulberry) root bark fractions supplementation in cholesterol-fed rats. Life Sci. 2006;78(23):2724-33. doi: 10.1016/j.lfs.2005.10.010.

21. Arnault E, Doussau M, Pesty A, Gouget B, Van der Meeren A, Fouchet P, et al. Natural uranium disturbs mouse folliculogenesis in vivo and oocyte meiosis in vitro. Toxicology. 2008;247(2-3):80-7. doi: 10.1016/j. tox.2008.02.006.

22. Sadeghi A, Farokhi F, Shalizar-Jalali A, Najafi G. Protective effect of vitamin $\mathrm{E}$ on sperm quality and in vitro fertilizing potential and testosterone concentration in polyvinyl chloride treated male rats. Vet Res Forum. 2020;11(3):25763. doi: 10.30466/vrf.2019.91184.2206.

23. Aebi H. Catalase in vitro. Methods Enzymol. 1984;105:1216. doi: 10.1016/s0076-6879(84)05016-3.
24. Katalinic V, Modun D, Music I, Boban M. Gender differences in antioxidant capacity of rat tissues determined by 2,2'-azinobis (3-ethylbenzothiazoline 6-sulfonate; ABTS) and ferric reducing antioxidant power (FRAP) assays. Comp Biochem Physiol C Toxicol Pharmacol. 2005;140(1):47-52. doi: 10.1016/j.cca.2005.01.005.

25. Morgante G, Massaro MG, Di Sabatino A, Cappelli V, De Leo V. Therapeutic approach for metabolic disorders and infertility in women with PCOS. Gynecol Endocrinol. 2018;34(1):4-9. doi: 10.1080/09513590.2017.1370644.

26. Amjad S, Baig M, Zahid N, Tariq S, Rehman R. Association between leptin, obesity, hormonal interplay and male infertility. Andrologia. 2019;51(1):e13147. doi: 10.1111/ and.13147.

27. Francisco V, Pino J, Campos-Cabaleiro V, Ruiz-Fernández C, Mera A, Gonzalez-Gay MA, et al. Obesity, fat mass and immune system: role for leptin. Front Physiol. 2018;9:640. doi: 10.3389/fphys.2018.00640.

28. Arai Y, Choi B, Kim BJ, Rim W, Park S, Park H, et al. Tauroursodeoxycholic acid (TUDCA) counters osteoarthritis by regulating intracellular cholesterol levels and membrane fluidity of degenerated chondrocytes. Biomater Sci. 2019;7(8):3178-89. doi: 10.1039/c9bm00426b.

29. Fekete C, Lechan RM. Central regulation of hypothalamicpituitary-thyroid axis under physiological and pathophysiological conditions. Endocr Rev. 2014;35(2):15994. doi: 10.1210/er.2013-1087.

30. Yding Andersen C. Inhibin-B secretion and FSH isoform distribution may play an integral part of follicular selection in the natural menstrual cycle. Mol Hum Reprod. 2017;23(1):16-24. doi: 10.1093/molehr/gaw070.

31. Regan SLP, Knight PG, Yovich JL, Leung Y, Arfuso F, Dharmarajan A. Granulosa cell apoptosis in the ovarian follicle-a changing view. Front Endocrinol (Lausanne). 2018;9:61. doi: 10.3389/fendo.2018.00061.

32. Dludla PV, Nkambule BB, Jack B, Mkandla Z, Mutize $\mathrm{T}$, Silvestri $\mathrm{S}$, et al. Inflammation and oxidative stress in an obese state and the protective effects of gallic acid. Nutrients. 2018;11(1):23. doi: 10.3390/nu11010023.

33. Kurzawa R, Ciepiela P, Baczkowski T, Safranow K, Brelik P. Comparison of embryological and clinical outcome in $\mathrm{GnRH}$ antagonist vs. GnRH agonist protocols for in vitro fertilization in PCOS non-obese patients. A prospective randomized study. J Assist Reprod Genet. 2008;25(8):36574. doi: 10.1007/s10815-008-9249-7.

34. Borzoei A, Rafraf M, Niromanesh S, Farzadi L, Narimani F, Doostan F. Effects of cinnamon supplementation on antioxidant status and serum lipids in women with polycystic ovary syndrome. J Tradit Complement Med. 2018;8(1):128-33. doi: 10.1016/j.jtcme.2017.04.008.

35. Cordier AG, Léveillé P, Dupont C, Tarrade A, Picone O, Larcher T, et al. Dietary lipid and cholesterol induce ovarian dysfunction and abnormal LH response to stimulation in rabbits. PLoS One. 2013;8(5):e63101. doi: 10.1371/journal. pone.0063101.

36. Ekeleme-Egedigwe CA, Famurewa AC, David EE, Eleazu CO, Egedigwe UO. Antioxidant potential of garlic oil supplementation prevents cyclophosphamide-induced oxidative testicular damage and endocrine depletion in rats. J Nutr Intermed Metab. 2019;18:100109. doi: 10.1016/j. jnim.2020.100109.

37. Ahmadi Y, Mahmoudi N, Yousefi B, Karimian A. The 
effects of statins with a high hepatoselectivity rank on the extra-hepatic tissues; new functions for statins. Pharmacol Res. 2020;152:104621. doi: 10.1016/j.phrs.2019.104621.

38. Fuentes E, Gibbins JM, Holbrook LM, Palomo I. NADPH oxidase 2 (NOX2): a key target of oxidative stress-mediated platelet activation and thrombosis. Trends Cardiovasc Med. 2018;28(7):429-34. doi: 10.1016/j.tcm.2018.03.001.

39. Petropoulos S, Fernandes Â, Barros L, Ciric A, Sokovic M,
Ferreira ICFR. Antimicrobial and antioxidant properties of various Greek garlic genotypes. Food Chemi. 2018;245:712. doi: 10.1016/j.foodchem.2017.10.078.

40. Hamzeh M, Hosseinimehr SJ, Khalatbary AR, Mohammadi HR, Dashti A, Talebpour Amiri F. Atorvastatin mitigates cyclophosphamide-induced hepatotoxicity via suppression of oxidative stress and apoptosis in rat model. Res Pharm Sci. 2018;13(5):440-9. doi: 10.4103/1735-5362.236837. 